\title{
Mycorrhization of Quercus acutissima with Chinese black truffle significantly altered the host physiology and root- associated microbiomes
}

\author{
Xiaoping Zhang ${ }^{1,2}$, Lei Ye ${ }^{1}$, Zongjing Kang ${ }^{1,2}$, Jie Zou ${ }^{1,2}$, Xiaoping Zhang ${ }^{\text {Corresp., }}{ }^{2}$, Xiaolin Li ${ }^{\text {Corresp. } 1}$ \\ ${ }^{1}$ Soil and Fertilizer Institute, Sichuan Academy of Agriculture Sciences, Chengdu, China \\ 2 Department of Microbiology, College of Resources, Sichuan Agricultural University, Chengdu, China \\ Corresponding Authors: Xiaoping Zhang, Xiaolin Li \\ Email address: aumdwsb@sicau.edu.cn, kerrylee_tw@sina.com
}

Background Our aim was to explore how the ectomycorrhizae of an indigenous tree, Quercus acutissima, with a commercial truffle, Chinese black truffle (Tuber indicum), affects the host plant physiology and shapes the associated microbial communities in the surrounding environment during the early stage of symbiosis.

Methods To achieve this, changes in root morphology and microscopic characteristics, plant physiology indices, and the rhizosphere soil properties were investigated when six-month-old ectomycorrhizae were synthesized. Meanwhile, next-generation sequencing technology was used to analyze the bacterial and fungal communities in the root endosphere and rhizosphere soil inoculated with $T$. indicum or not.

Results The results showed that colonization by $T$. indicum significantly improved the activity of superoxide dismutase in roots but significantly decreased the root activity. The biomass, leaf chlorophyll content and root peroxidase activity did not differ obviously. Ectomycorrhization of $Q$. acutissima with $T$. indicum affected the characteristics of the rhizosphere soil, improving the content of organic matter, total nitrogen, total phosphorus and available nitrogen. The bacterial and fungal community composition in the root endosphere and rhizosphere soil was altered by $T$. indicum colonization, as was the community richness and diversity. The dominant bacteria in all the samples were Proteobacteria and Actinobacteria, and the dominant fungi were Eukaryota_norank, Ascomycota, and Mucoromycota. Some bacterial communities, such as Streptomyces, SM1A02, and Rhizomicrobium were more abundant in the ectomycorrhizae or ectomycorrhizosphere soil. Tuber was the second-most abundant fungal genus, and Fusarium was present at lower amounts in the inoculated samples.

Discussion Overall, the symbiotic relationship between $Q$. acutissima and $T$. indicum had an obvious effect on host plant physiology, soil properties, and microbial community composition in the root endosphere and rhizosphere soil, which could improve our understanding of the symbiotic relationship between $Q$. acutissima and $T$. indicum, and may contribute to the cultivation of truffle. 
1

2

3

4

5

6

7 China;

7

\section{Mycorrhization of Quercus acutissima with Chinese black truffle significantly altered the host physiology and root- associated microbiomes}

Xiaoping Zhang ${ }^{1,2 \#}$, Lei Ye ${ }^{1 \#, ~ Z o n g j i n g ~ K a n g ~}{ }^{1,2}$, Jie Zou ${ }^{1,2}$, Xiaoping Zhang ${ }^{*}$, Xiaolin Li ${ }^{*}$

${ }^{1}$ Soil and Fertilizer Institute, Sichuan Academy of Agriculture Sciences, Chengdu, China;

${ }^{2}$ Department of Microbiology, College of Resources, Sichuan Agricultural University, Chengdu,

\# Xiaoping Zhang and Lei Ye contributed equally to the work.

* Corresponding Author:

Xiaoping Zhang

Huimin Road, Chengdu, 611130, China

Email address: zhangxiaopingphd@126.com

Xiaolin Li

Shizishan Road, Chengdu, 610066, China

Email address: kerrylee tw@sina.com 
23 Abstract:

Background Our aim was to explore how the ectomycorrhizae of an indigenous tree, Quercus acutissima, with a commercial truffle, Chinese black truffle (Tuber indicum), affects the host plant physiology and shapes the associated microbial communities in the surrounding environment during the early stage of symbiosis.

Methods To achieve this, changes in root morphology and microscopic characteristics, plant physiology indices, and the rhizosphere soil properties were investigated when six-month-old ectomycorrhizae were synthesized. Meanwhile, next-generation sequencing technology was used to analyze the bacterial and fungal communities in the root endosphere and rhizosphere soil inoculated with $T$. indicum or not.

Results The results showed that colonization by $T$. indicum significantly improved the activity of superoxide dismutase in roots but significantly decreased the root activity. The biomass, leaf chlorophyll content and root peroxidase activity did not differ obviously. Ectomycorrhization of Q. acutissima with $T$. indicum affected the characteristics of the rhizosphere soil, improving the content of organic matter, total nitrogen, total phosphorus and available nitrogen. The bacterial and fungal community composition in the root endosphere and rhizosphere soil was altered by $T$. indicum colonization, as was the community richness and diversity. The dominant bacteria in all the samples were Proteobacteria and Actinobacteria, and the dominant fungi were Eukaryota_norank, Ascomycota, and Mucoromycota. Some bacterial communities, such as Streptomyces, SM1A02, and Rhizomicrobium were more abundant in the ectomycorrhizae or ectomycorrhizosphere soil. Tuber was the second-most abundant fungal genus, and Fusarium was present at lower amounts in the inoculated samples.

Discussion Overall, the symbiotic relationship between Q. acutissima and T. indicum had an obvious effect on host plant physiology, soil properties, and microbial community composition in the root endosphere and rhizosphere soil, which could improve our understanding of the symbiotic relationship between $Q$. acutissima and $T$. indicum, and may contribute to the cultivation of truffle. 


\section{Introduction}

T. indicum, an Asian black truffle that is phylogenetically and morphologically related to Périgord black truffle (T. melanosporum Vittad), is the major commercial truffle species in China and is a highly economically valued edible fungus (Liu et al., 2011). Since its discovery and export to Europe in the 1990s, T. indicum has attracted increasing attention (Geng et al., 2009). As ectomycorrhizal fungi characterized by hypogeous fruiting bodies, truffles need to infect host plants and develop a symbiosis with them to complete their lifecycle (Kües and Martin, 2011; Healy et al., 2016). At present, truffle cultivation mainly focuses on synthesizing truffle-colonized seedlings and establishing truffle plantations (Liu et al., 2011). T. indicum has a wide adaptability to host plants, and it's specificity of colonization is not absolute. It can establish symbiotic associations with the roots of Pinus armandii, Cyclobalanopsis glauca, Quercus aliena, Populus bonatii, Carya illinoinensis, and Corylus avellana, to name a few, which includes Chinese trees, North American trees, and European trees (Hu, 2004; Bonito et al., 2011; Deng et al., 2014). Q. acutissima is an indigenous Chinese broad leaf tree that is widely distributed in China. At present, successful mycorrhizal synthesis with T. indicum has been observed for $Q$. acutissima (Hu, 2004).

As ectomycorrhizal fungi, truffles can maintain the stability and health of ecosystems in the natural environment to a certain extent, which has important ecological value (Liu et al., 2011). During the life cycle of truffles, from mycelium germination to the harvesting of the fruiting bodies, some volatile metabolites are released, and these metabolites can inhibit the germination of the surrounding seeds and other biological communities, creating a brûlé area (Streiblová et al., 2012). Some reports showed that bacteria and fungi diversity in the brûlé area is lower, and thus truffles are inferred to affect the associated soil microbial communities (Mello et al., 2013; Zampieri et al., 2016). Although the microbial community in the surrounding environment varied with different truffles species, truffle growth periods, and different regions and seasons, they were found important to the formation of ectomycorrhizae and truffle ascocarps, as well as their aroma (Barbieri et al., 2007; Splivallo et al., 2015; Benucci and Bonito, 2016; Deveau et al., 
2016). Some bacteria in rhizosphere soil were screened and confirmed to benefit the synthesis of ectomycorrhizae, referred to as "mycorrhization helper bacteria" (Wang et al., 2015; Fu et al., 2016). In addition, a diverse microbial community consisting of bacteria, yeast, and filamentous fungi was found in the ectomycorrhizae and fruiting bodies of truffles, many of which are endophytes (Zhou and Wei, 2013; Splivallo et al., 2015). Endophytes can produce bioactive compounds, participate in the host metabolic processes, and play important roles in the growth and fitness of plants (Hardoim et al., 2015; Ludwig-Müller, 2015). These microorganisms are closely associated with truffle growth and their interaction with truffles may be key to the artificial cultivation that is currently lacking. Additionally, the colonization of ectomycorrhizal fungi with root system can improve the soil structure, and the soil characteristics also influence truffle ectomycorrhizae development and sporocarp formation (Alonso et al., 2014). Furthermore, ectomycorrhizal fungi can improve water absorption and nutrient utilization by host plants, which is beneficial to plant growth. Following ectomycorrhizal formation, the expression of some defense genes induced by plants enhances the biotic and abiotic stress resistance of host plants, including drought resistance, disease resistance, and pest resistance (Kennedy, 2010; Lilleskov et al., 2011).

Although truffles have been studied for many years, their complex growth mechanisms are not well understood and successful artificial cultivation has not been achieved. Previous studies focused greatly on the mycorrhization of seedlings with truffles and the microbial communities associated with truffles, including microbes in the soil and ascocarps. However, how these microbial communities play their roles in truffle formation, and the relationship and interaction between the ectomycorrhizae, microorganisms, and host plants, is unclear. We thus synthetized the ectomycorrhizae of $Q$. acutissima with $T$. indicum to explore the effect of $T$. indicum colonization on the host plant. Changes in root morphology and physiology, and the rhizosphere soil properties were also detected. In addition, we explored the influence of the symbiotic relationship of $Q$. acutissima and $T$. indicum on bacterial and fungal community composition in the root endosphere and rhizosphere soil using high-throughput sequencing. We hypothesized 
104 that the truffles colonization could alter the host plant physiology, and the microbiome in 105 rhizosphere soil and root endosphere would be shaped in response to the truffle 106 ectomycorrhization, which could contribute to reveal the ecological mechanisms of truffle during 107 the early symbiotic stages, with the aim of providing a foundation for the artificial cultivation of 108 truffles.

\section{Materials and methods}

110

111

\section{Cultivation of $Q$. acutissima seedlings and truffle inoculation treatment}

The Q. acutissima seeds were obtained from Taian city, Shandong province, China. The seeds were washed with water to remove impurities and then soaked in $0.5 \%$ potassium permanganate solution for $2 \mathrm{~h}$. Following this, the seeds were surface-sterilized with ultra-pure water and then sowed in nursery substrate, as detailed in a previous report (Li et al., 2017). After 2 months, the seedlings that exhibited good growth and were of similar height were selected for the root-tip cutting treatment. Root-tip cutting is an efficient technique for plant growth management (Shabala et al., 2009). Approximately $1 \mathrm{~cm}$ of root tip from the taproots was removed with sterilized scissors. The $Q$. acutissima seedlings that had their roots-tips removed were then respectively transplanted into a plastic container (about $155 \mathrm{~mL}$ ) with sterilized cultivation substrate. The cultivation substrate $(\mathrm{pH} 7.5)$ was composed of peat, organic soil (from Yuexi County in Sichuan, China), vermiculite, and water at a volume ratio of 1:1:1:1.5. Inoculation was performed at the same time the plants were transplanted.

T. indicum was purchased from Huidong County, China. The ascocarps, which had been surface disinfected with $75 \%$ alcohol, were pulverized and blended to obtain the spore powder (Wan et al., 2015). Two grams of spore powder was inoculated into the cultivation substrate. The uninoculated $Q$. acutissima seedlings were used as controls. The number of inoculated and uninoculated $Q$. acutissima seedlings (controls) was both sixty. Three biological replicates were set in each treatment, so each bioreplicate had 20 seedlings. All seedlings were cultivated in greenhouses under the same conditions (Fig. S1). During the cultivation period, plants were irrigated with tap water every 2 or $3 \mathrm{~d}$. 
131

132

133

134

135

136

137

138

139

140

141

142

143

144

145

146

147

148

149

150

151

152

153

154

155

156

157

\section{Sample collection and analysis}

Six months after inoculation, the plant root tips and the rhizosphere soil in the cultivation substrate were collected. Briefly, take the seedlings (mycorrhization with T. indicum and uninoculated seedlings) out of the substrate and collect the rhizosphere soils with sterilized gloves. The soils used for high-throughput sequencing were stored in $2 \mathrm{ml} \mathrm{EP}$ tubes in $-80^{\circ} \mathrm{C}$ refrigerator and the soils used for properties determination were dried and then stored in plastic bag at room temperature. The properties of the ectomycorrhizosphere soil (soil around the roots mycorrhization with $T$. indicum) and rhizosphere soil (soil around the roots of uninoculated plants) samples were measured according to the previous method (Li et al., 2016), including pH, organic matter (OM), total nitrogen (TN), available nitrogen (AN), total phosphorus (TP), available phosphorus (AP), total potassium (TK), available potassium (AK), available calcium (ACa), and available magnesium (AMg). As for $Q$. acutissima seedlings, clean the roots with water and the morphological analysis of the ectomycorrhizae from $Q$. acutissima roots was performed by microscope. The number of root segments colonized by T. indicum was counted according to the mycorrhizal fungal structures, with a total of 30 root segments randomly selected and observed for each seedling (Andrés-Alpuente et al., 2014). The mycorrhizal colonization rate was calculated from this, expressed as: mycorrhizal colonization rate $(\%)=$ (root segments colonized by $T$. indicum / total root segments observed) $\times 100$. After identifying the mycorrhizae, the $Q$. acutissima roots, including two treatments (roots colonized with truffle mycelia and uncolonized roots) were surface disinfected, after which their DNA was extracted for high-throughput sequencing. Each treatment had three repetitions and each repetition was at least $1 \mathrm{~g}$. The ectomycorrhizae of $Q$. acutissima with $T$. indicum were assigned to "A," and the ectomycorrhizosphere soil was assigned to "B". Roots from the control plants that were not colonized with T. indicum belonged to "D," and the rhizosphere soil belonged to "C". All samples had three replicates.

\section{Determination of plant physiological indices}

The root activity, biomass, chlorophyll content in leaves, activities of superoxide dismutases 
158

159

160

161

162

163

164

165

166

167

168

169

170

171

172

173

174

175

176

177

178

179

180

181

182

183

184

(SOD) and peroxidase (POD) in roots were measured. The root activity determination was based on triphenyl tetrazolium chloride (TTC) method described by Zhang et al. (2013). Briefly, put $0.5 \mathrm{~g}$ fresh root in the $10 \mathrm{~mL}$ solution mixed with $5 \mathrm{~mL} 0.4 \%$ TTC solution and equal volumes of phosphate buffer. The mixed solution was then kept in oven at $37^{\circ} \mathrm{C}$ for $2 \mathrm{~h}$. Then add $2 \mathrm{~mL} 1$ $\mathrm{mol} / \mathrm{L} \mathrm{H}_{2} \mathrm{SO}_{4}$ to the mixed solution. Dry the root and grind roots fully with ethyl acetate in a mortar, finally with ethyl acetate to $10 \mathrm{~mL}$. The liquid was measured at the $485 \mathrm{~nm}$ of a spectrophotometer to get the absorbance. Root activity $=$ the amount of TTC reduction $(\mu \mathrm{g}) /$ fresh root weight $(\mathrm{g}) \times$ time $(\mathrm{min})$.

The biomass of each seedling was assessed based on the aboveground and belowground dry matter weight. For dry weight determination, the seedlings were first washed to remove any substrate attached to the roots, after which they were oven-dried at $105^{\circ} \mathrm{C}$ for $30 \mathrm{~min}$ to halt respiration, and then oven-dried at $75^{\circ} \mathrm{C}$ to achieve constant weight (Moore et al. 2010). The dry weight of aboveground and belowground parts was measured once the material had cooled.

Chlorophyll content was measured spectrophotometrically using fresh leaf samples without main vein. The same sections of the leaves at the center of $Q$. acutissima seedlings were selected and determined according to previous method (Taïbi et al., 2016). Briefly, slice the leaves and grind them fully with $80 \%$ acetone $(\mathrm{v} / \mathrm{v})$. The extraction was filtered and the volume of it was added to $10 \mathrm{~mL}$ with acetone. The absorbance of the extraction was recorded at 663 and $645 \mathrm{~nm}$ for calculations of chlorophyll content. Chlorophyll content expressed with (mg)/fresh leaf weight $(\mathrm{g})$.

SOD and POD are antioxidant enzymes. The SOD activity was determined according to its ability to inhibit the photochemical reduction of nitroblue tetrazolium (NBT), following the method of Fridovich (Fridovich, 2011). POD activity was measured using the guaiacol method with the theory that $\mathrm{H}_{2} \mathrm{O}_{2}$ can oxidize the guaiacol under the catalysis of peroxidase, following the method of Meloni (Meloni, 2003).

All the determinations were repeated at least three times.

\section{DNA extraction, PCR amplification, and HiSeq sequencing}


DNA of the tissues and endophytes in the roots was extracted with the hexadecyl trimethyl

186

187

ammonium bromide (CTAB) method (Li et al., 2017). DNA of the rhizosphere soil samples was extracted using a MoBio PowerSoil® DNA Isolation Kit. The extracted DNA was detected by $1 \%$ agarose gel electrophoresis.

The 16S V4 and ITS1 region amplification of all samples was respectively performed by the universal primers 515F (5'-GTGCCAGCMGCCGCGGTAA-3') - 806R (5'-GGACTACH VGGGTWTCTAAT-3') and ITS1F (5'-CTTGGTCATTTAGAGGAAGTAA-3') - ITS2 (5'GCTGCGTTCTTCATCGATGC-3') with the barcode on ABI GeneAmp® 9700 PCR instrument (Caporaso, 2012; Huang et al., 2015). After mixing and detecting with 2\% agarose gel electrophoresis, the PCR products were recycled and purified with Agencourt AMPure Beads (Beckman Coulter, Indianapolis, IN). Finally, the PCR products were quantified using Quant-iT PicoGreen dsDNA Assay Kit and then mixed in proportion according to the concentration of each sample.

PCR amplicon libraries were generated by an Illumina TruSeq Nano DNA LT Sample Prep Kit (FC-121-4001). The library quality was then assessed and amplicon sequencing was performed on an Illumina HiSeq 2500 platform, generating $2 \times 300$ bp sequences. All raw data were submitted to the Sequence Read Archive (SRA) database with the accession numbers SRR7791517-SRR7791532.

\section{Sequence data processing and statistical analysis}

The raw data were firstly saved in FASTQ format. The obtained reads were firstly spliced according to the overlap relation and then quality-controlled and filtered. Trimmomatic, FLASH, Usearch, and QIIME software were used for these processes (Caporaso, 2010; Magoč and Salzberg, 2011). High-quality sequences more than 97\% similarity were classified into an OTU with UCLUST (Edgar, 2010). To obtain the classification information for each OTU species, the RDP classifier was used for the taxonomic analysis of OTU representative sequences based on the SILVA (Release119 http://www.arb-silva.de) and Unite (Release 6.0 http://unite.ut.ee/index.php) databases. Rarefaction curves were used to estimate coverage. The 
212 alpha-diversity indices including Chao1, Shannon, and Simpson were analyzed with QIIME 213 (version 1.7.0). The beta diversity which indicates the differences of microbial communities 214 among the samples was reflected by Non-metric multidimensional scaling (NMDS). Meanwhile, 215 Analysis of similarity (ANOSIM) was used to test significant differences between the treatments. 216 The shared OTUs were presented in a Venn diagram. Heatmaps were drawn using R software (R 217 Core Team, 2014) in order to cluster and analyze the more abundant phyla and genera in samples 218 and to evaluate the taxonomic composition of the microbial communities. LEfSe (linear 219 discriminant analysis, LDA) was performed to reveal the taxa of microbial communities that had

220

221

222

223

224

225

226

227

228

229

230

231

232

233

234

235

236

237

238 differential abundance in the different treatments at all taxonomic levels.

One-way analysis of variance (ANOVA) and independent sample $t$-tests were performed in in SPSS v21.0 (IBM Inc., Armonk, NY, USA). T-tests were used for the analysis of soil properties and plant physiological indices. The least significant difference (LSD) was performed to determine the significant pairwise differences between different treatments. All significant differences were assessed at $P<0.05$.

\section{Results}

\section{The effect of $T$. indicum inoculation on $Q$. acutissima}

Six months after inoculation of T. indicum, mycorrhization was successfully detected in the inoculated Q. acutissima seedlings, and the calculated mycorrhizal colonization rate was 52.07\% $\pm 13.52 \%$. The seedlings that were not inoculated with truffle spores exhibited obvious differences in their root systems based on morphological analysis (Fig. 1 and Fig. 2). It was evident that the synthesized ectomycorrhizae were monopodial or binary branched and were yellowish-brown.

The root activity, biomass, chlorophyll content in leaves, and SOD and POD activity in the roots of Q. acutissima are shown in Table 1. POD activity, biomass and chlorophyll content did not differ significantly between the inoculated and control seedlings. SOD activity increased significantly in the $Q$. acutissima seedlings following inoculation with $T$. indicum compared with the control seedlings $(P<0.05)$. However, the root activity was significantly lower in the $Q$. 
239

240

241

242

243

244

245

246

247

248

249

250

251

252

253

254

255

256

257

258

259

260

261

262

263

264

265

acutissima seedlings colonized by $T$. indicum $(P<0.05)$.

\section{Soil properties analysis}

Some physicochemical properties of the soil samples collected from the Q. acutissima roots are presented in Table 2, including those associated with both the inoculated and uninoculated treatments. With the exception of total potassium and available magnesium, the remaining parameters (including $\mathrm{pH}$, organic matter, total nitrogen, total phosphorus, available nitrogen, available phosphorus, available potassium, and available calcium) all differed significantly between the ectomycorrhizosphere soil and rhizosphere soil (control treatment) $(P<0.05)$. The content of total phosphorus was significantly higher in the ectomycorrhizosphere soil $(P<0.05)$, increasing by $9 \%$ compared with that in rhizosphere soil, while the available phosphorus was significantly lower, decreasing by $11 \%(P<0.05)$. The content of organic matter, total nitrogen, and available nitrogen were all also significantly higher in the ectomycorrhizosphere soil than the rhizosphere soil $(P<0.05)$, increasing by $3 \%, 1 \%$ and $6 \%$, respectively. Inoculation with $T$. indicum thus improved the carbon and nitrogen levels in the rhizosphere soil. However, the rhizosphere soil had significantly higher $\mathrm{pH}$, available potassium, and available calcium $(P<0.05)$.

\section{Alpha diversity of bacterial community}

A total of 323,364 high- quality sequences were obtained from the 12 samples after quality control procedures, and there were 18,333-33,288 high-quality sequences in each sample (Fig. S2a). The sequences from each sample were classified into 578-1344 OTUs. The Venn diagram displayed the degree of overlap of the bacterial OTUs among the samples of the four treatments, and 72, 79, 298, and 109 unique OTUs were identified in each treatment, respectively (Fig. 3a). A total of 30 phyla, 88 classes, 148 orders, 275 families, and 522 genera of bacteria and archaea were detected.

The bacterial alpha diversity indices, including observed species (OTU), Chao1, Shannon, and Simpson, are shown in Table 3a. The number of observed species and the Chaol index, which indicate the community richness, were significantly higher in the uninoculated rhizosphere 
266

267

268

269

270

271

272

273

274

275

276

277

278

279

280

281

282

283

284

285

286

287

288

289

290

291

292

soil than in the other samples $(P<0.05)$, indicating that $T$. indicum colonization significantly decreased the bacteria community richness in the rhizosphere soil of $Q$. acutissima. The observed species and Chaol were lower in the ectomycorrhizae than in the control roots, but did not reach a significant level. The Shannon and Simpson indices represent the community diversity, the greater the Shannon value, the higher the community diversity, while the larger the Simpson index, the lower the community diversity. The ectomycorrhizae had a significantly higher Shannon index $(P<0.05)$ and significantly lower Simpson index $(P<0.05)$, illustrating a higher bacterial diversity than the control roots. The Shannon index was highest in the uninoculated rhizosphere soil samples, while the Simpson index was lowest, indicating that inoculation with $T$. indicum could significantly decrease the bacterial diversity in the rhizosphere soil of the seedlings $(P<0.05)$. Inoculation with $T$. indicum thus clearly influenced the bacterial richness and diversity in the root endosphere and rhizosphere soil.

\section{Alpha diversity of fungal community}

A total of 413,105 sequences were obtained from the 12 samples after quality control procedures, and there were 32,024-36,641 high-quality sequences in each sample (Fig. S2b). These high-quality sequences were clustered into 37-181 OTUs, representing five phyla, 13 classes, 33 orders, 59 families, and 89 genera. The Venn diagram is shown in Fig. $3 b$.

The number of observed species (OTU) differed significantly between the four treatments and was also significantly higher in the uninoculated rhizosphere soil $(P<0.05)$ (Table $3 \mathrm{~b})$. The Chaol index differed significantly between the control treatments and the treatments associated with $T$. indicum $(P<0.05)$. The OTU and Chaol indices indicated that the fungal community richness was significantly higher in the treatments without $T$. indicum colonization $(P<0.05)$. Inoculation with $T$. indicum decreased the fungal richness. Significant differences in the Shannon and Simpson indices were also observed between the uninoculated and inoculated samples $(P<0.05)$. The indices demonstrated that inoculation with $T$. indicum had an obvious impact on the fungal diversity, and T. indicum significantly decreased the fungal diversity in the root endosphere and rhizosphere soil $(P<0.05)$. 
293

294

295

296

297

298

299

300

301

302

303

304

305

306

307

308

309

310

311

312

313

314

315

316

317

318

319

\section{Bacterial and fungal Unifrac-NMDS analysis}

Unifrac-NMDS analysis was used to visualize the beta diversity of the bacterial and fungal communities in the different samples, which presents the similarities and differences in bacteria and fungi between the samples (Fig. 4). There were significant differences in bacterial community structure and composition between the four treatments (ANOSIM: $\mathrm{R}>0.9, P=$ 0.001) (Fig 4a).

The fungal community structures were very similar between the control root endosphere and control soil, and differed significantly from the treatments associated with T. indicum inoculation (ANOSIM: $\mathrm{R}>0.9, P=0.001$ ) (Fig 4b). Thus, inoculation with truffles altered the fungal community composition in the root endosphere and rhizosphere soil.

\section{Taxonomic composition of the bacterial and fungal communities}

The composition of bacterial communities at the phylum level was shown in Fig. 5a. A total of 30 phyla were identified, but only 14 phyla were detected in all 12 samples. Proteobacteria (52.4\%), Actinobacteria (23.7\%), Planctomycetes (6.5\%), Acidobacteria (5.3\%), Bacteroidetes (3.7\%), and Chloroflexi (1.8\%) were the six dominant phyla in all samples, accounting for 93.4\% (average relative abundance) of all bacteria communities. At the class level, Proteobacteria_Unclassified (25.2\%), Alphaproteobacteria (16.4\%), Actinobacteria (16.0\%), Gammaproteobacteria (7.6\%), and Thermoleophilia (5.2\%) were most abundant, all of which belong to Proteobacteria or Actinobacteria. At the genus level (Fig. S3a), the dominant genera included Proteobacteria_Unclassified (25.2\%), Streptomyces (8.6\%), Pantoea (5.3\%), Patulibacter (2.3\%), SM1A02 (2.2\%), and Elev-16S-1332_norank (1.9\%).

The fungal community structure composition at the phylum level was shown in Fig. 5b. There were a total of five phyla in all the samples, including Ascomycota, Basidiomycota, Eukaryota_norank, Mucoromycota, and Unclassified. Among them, Ascomycota accounted for the relative abundance of $44.09 \%$. At the class level, Eukaryota_norank (50.19\%), Pezizomycetes (22.19\%), and Sordariomycetes (17.14\%) were the three most dominant. In addition, Dothideomycetes had a relative abundance of $4.10 \%$. At the genus level (Fig. S3b), 
320

321

322

323

324

325

326

327

328

329

330

331

332

333

334

335

336

337

338

339

340

341

342

343

344

345

346

only six common genera existed in each sample of a total of 89 genera. The second-most abundant observed genus was Tuber (21.58\%), and other genera with high relative abundances included Humicola (7.10\%), Fusarium (5.81\%), Pleosporales_norank (3.20\%), Collariella $(1.56 \%)$, and Trichoderma $(0.72 \%)$.

\section{Differential analysis of bacterial and fungal communities}

The abundances of some bacterial and fungal communities differed in the different samples. In terms of bacteria (Fig. S4a.), the most abundant phylum, Proteobacteria, was significantly more abundant in the ectomycorrhizosphere soil than in the control soil $(P<0.05)$, whereas Proteobacteria was more abundant in the control root endosphere. On the contrary, the control soil and ectomycorrhizae contained more Actinobacteria than the ectomycorrhizosphere soil $(P<0.05)$ and control roots, respectively. Acidobacteria and Bacteroidetes were significantly more abundant in the ectomycorrhizosphere soil $(P<0.05)$, and were more abundant in the inoculated treatments than in the control treatments. At the class level (Fig. 6a), Alphaproteobacteria, Betaproteobacteria, Deltaproteobacteria, and Acidimicrobiia had significantly higher abundance in the ectomycorrhizosphere soil $(P<0.05)$, while Thermoleophilia and Planctomycetacia were significantly more abundant in the control soil $(P<0.05)$. The ectomycorrhizae contained more Gammaproteobacteria than the control roots $(P<0.05)$. At the genus level (Fig. 7a), the samples associated with $T$. indicum inoculation had more Streptomyces and SM1A02 than the control treatments, and the differences reached a significant level in soil samples $(P<0.05)$. Kribbella and Variibacter were more abundant in the ectomycorrhizae than in the control roots $(P<0.05)$, while Patulibacter, Kribbella, Variibacter, Planctomyces, and Elev-16S-1332_norank were more abundant in the control soil than in the ectomycorrhizosphere soil $(P<0.05)$. The ectomycorrhizosphere soil contained significantly more Subgroup 7_norank, Rhizomicrobium, and Cytophagaceae_uncultured than the control soil $(P<0.05)$.

45 In terms of fungi (Fig. S4b), ectomycorrhizosphere soil contained significantly more Ascomycota $(P<0.05)$, and its abundance was lowest in the ectomycorrhizae. Pezizomycetes was 
347

348

349

350

351

352

353

354

355

356

357

358

359

360

361

362

363

364

365

366

367

368

369

370

371

372

373

most abundant in the ectomycorrhizosphere soil (Fig. 6b), and its relative abundance was higher in the inoculated treatments than the inoculated treatments. The abundance of Sordariomycetes was higher in the treatments without $T$. indicum inoculation $(P<0.05)$. At the genus level (Fig. 7b), Tuber was only detected in the ectomycorrhizae and ectomycorrhizosphere soil with an average relative abundance of $43.11 \%$, and was significantly more abundant in the ectomycorrhizosphere soil $(P<0.05)$. The abundances of Humicola, Fusarium, Collariella, and Trichoderma were significantly higher in the control samples $(P<0.05)$.

\section{Discussion}

As ectomycorrhizal fungi, truffles have an important function in the ecosystem. Ectomycorrhizal fungal communities can alter forest soil biogeochemistry, as observed in $T$. melanosporum and T. aestivum (Fu et al., 2016). However, whether the truffles can colonize the root tips of plants and successfully form ectomycorrhizae is not only determined by the surrounding abiotic factors, like the temperature and humidity, the soil $\mathrm{pH}$ and soil fertility, but also determined by biotic factors, such as soil microorganisms and vegetation (Slankis, 1974). In this study, we thus inoculated $T$. indicum on $Q$. acutissima to analyze how this affects the physiology of the host plant and shapes the soil properties and microbial communities in the root endosphere and rhizosphere soil during the early stage of symbiosis.

Ectomycorrhizae are beneficial to host plants in terms of water and nutrient uptake and host resistance (Harley and Smith, 2008). Previous studies showed that the symbiosis of $T$. melanosporum with Pinus halepensis seedlings improved the absorption of nutrient and the growth of host plants (Dominguez et al., 2012). Another study indicated that the inoculation of $T$. indicum on several Chinese indigenous trees led to higher average plant heights, higher ground diameter increments, and higher disease resistance and biomass compared with the seedlings that were not inoculated $(\mathrm{Hu}, 2004)$. Plant growth was found to be closely related to the measured physiological indicators in our study. We found that SOD activity increased significantly in the inoculated roots compared with the uninoculated roots, whereas the root activity decreased significantly. However, POD activity, biomass and chlorophyll content didn't have significantly 
374

375

376

377

378

379

380

381

382

383

384

385

386

387

388

389

390

391

392

393

394

395

396

397

398

399

400

differences between the two different treatments. As the signaling compounds in transduction pathways, SODs play a very important role in plant physiology and act as inducers of cell damage when excessive production occurs at high concentrations (Che et al., 2016; Río et al., 2018). Increased SOD activity could be a response to abiotic stress in plants (Ding et al., 2017). The increase in SOD activity indicated that $T$. indicum inoculation improved the ability of the host plants to cope with stress. It is possible that during the early stage of symbiosis, the colonization of the seedling roots by the truffle hyphae to form ectomycorrhizae influences the environment around the roots, resulting in an increase in the metabolic activity of some substances in the roots, thereby altering the balance of active oxygen metabolism and causing increased SOD activity. Previous research showed that the root activity of Pinus massoniana inoculated with $T$. indicum was slightly higher compared with that of the seedlings without $T$. indicum colonization, which differed from our study (Yin and Zhu, 2008). Why T. indicum colonization decreased the root activity of $Q$. acutissima seedlings requires further study.

Soil parameter and nutrient availability dynamics might be crucial for supporting the lifecycle of truffle (Marjanović et al., 2015). The synthesis of truffle ectomycorrhizae was possibly related to the different soil properties (Garcíamontero et al., 2006). Our results showed that the ectomycorrhization of $Q$. acutissima with $T$. indicum affected the rhizosphere soil characteristics. Specifically, the organic matter, total nitrogen and available nitrogen, and total phosphorus were significantly higher in the ectomycorrhizosphere, indicating that the ectomycorrhizae of $T$. indicum promoted the release of nitrogen and phosphorus in the soil, particularly nitrogen, which would strengthen the absorption of these elements by the plant. A previous study showed that the formation of mycorrhizae of $Q$. petraea. with T. melanosporum increased the nitrogen content in plants, and the mycorrhization of Pinus halepensis Mill. with $T$. melanosporum improved the phosphorus uptake ( Domínguez et al., 2008). Other studies also confirmed that ectomycorrhizal fungi have the ability to improve nitrogen content (Chalot and Brun, 1998; Dearnaley and Cameron, 2017). However, the available phosphorus, available potassium, and available calcium were lower in the ectomycorrhizosphere, which differs from 
401 previous findings ( $\mathrm{Fu}$ et al., 2016; Li et al., 2017). It is possible that these soil nutrients are 402 relatively susceptible to the different conditions and different species. When establishing a new 403 plantation for truffle, we should take consideration of some soil chemical properties including

404

405

406

407

408

409

410

411

412

413

414

415

416

417

418

419

420

421

422

423

424

425

426

427

carbonates and $\mathrm{pH}$ (Valverde-Asenjo et al., 2009). T. indicum probably would like the slightly acidic soil, while T. melanosporum and T. magnatum prefer alkaline soil (Li et al., 2017).

The role of microorganisms in truffle formation is not to be underestimated and this may related to the changes of soil properties affected by truffle (Ge et al., 2017). Rhizosphere microbe communities can regulate mycorrhizal synthesis, and a symbiosis exists between some bacteria in the rhizosphere and the ectomycorrhizae. While these microbial communities promote the synthesis of ectomycorrhizae, the ectomycorrhizal fungi can also regulate the bacterial composition and function (Song et al., 2016). In our results, the colonization of $T$. indicum reduced the bacterial richness, fungal richness and fungal diversity in both the root endosphere and rhizosphere soil. Additionally, T. indicum colonization decreased the bacterial diversity in the rhizosphere soil but increased the bacterial diversity in the ectomycorrhizae. In addition, inoculation with $T$. indicum changed the composition of bacteria and fungus in the root endosphere and rhizosphere soil. Previous studies has provided evidence that neither in wild nor cultivated conditions, the diversity of bacterial and fungi reduced in the brûlé area as a result of truffles ensuring their survival by spreading their metabolites during their lifecycle (Mello et al., 2013). Interestingly, a previous report suggested that the volatiles released by truffles could inhibit both host and nonhost plants (Splivallo et al., 2007). Proteobacteria was found to be the most abundant bacteria in this study, and ectomycorrhizosphere soil and control roots contained more Proteobacteria. Many studies also showed that Proteobacteria was the dominant phylum in truffles fruiting bodies and in the different types of soils associated with Tuber (Gryndler et al., 2013; Antony-Babu et al., 2013; Ye et al., 2018). We also found that $\alpha$-Proteobacteria was most abundant in the ectomycorrhizosphere soil, and $\gamma$-Proteobacteria was most abundant in the ectomycorrhizae. Some reports indicated that $\alpha$-Proteobacteria and $\gamma$-Proteobacteria were the predominant truffle bacterial communities (Barbieri et al., 2007), which corroborates our results. 
428 In addition to Proteobacteria, we also detected Actinobacteria, Planctomycetes, and 429 Acidobacteria to be dominant bacteria. Streptomyces and SM1A02 may play important roles in 430 the mycorrhization of $Q$. acutissima with $T$. indicum, as the treatment associated with $T$. indicum 431 had significantly more Streptomyces and SM1A02. Streptomyces was also detected in the 432 ectomycorrhizae of T. aestivum in a previous study (Gryndler and Hršelová, 2012). In addition, 433 the ectomycorrhizosphere soil contained significantly more Rhizomicrobium. In terms of fungus, 434 Tuber was the second-most abundant fungus, accounting for $43.11 \%$ of the fungal community in 435 the ectomycorrhizae and ectomycorrhizosphere soil. Some species of Fusarium are pathogenic 436 fungi that produce fungal toxins (Gerlach and Nirenberg, 1982). Our study found a lower 437 abundance of Fusarium in the ectomycorrhizae and ectomycorrhizosphere soil, indicating that $T$. 438 indicum inoculation reduced some pathogenic fungi. Previous work suggested that 439 ectomycorrhizal fungi could protect the plant host during their growth, for example, they could 440 reduce the infection of plants by other microbes (Kennedy, 2010). Overall, the microbe 441 communities in the soil, ectomycorrhizae, and fruiting bodies, including bacteria, yeast, and 442 filamentous fungi, are important and closely related to the development and nutrition of truffle 443 ascocarps (Splivallo et al., 2015). Rhizosphere effects are huge on the root-associated microbial 444 community structure, which was an important reason why the root endophere microbial 445 community differed from rhizosophere community of Q. acutissima plants. Plants can induce or 446 shape rhizosphere microflora through their roots' secretion, and the pants genotype and soil type 447 are the important driving forces to microbial community structure (Berendsen et al., 2012; 448 Doornbos et al., 2012), which may be related to the mycorrhizae formation. Furthermore, there is 449 some interaction between the soil communities and endophytes. It was reported that both the 450 internal and external parts of truffles could be colonized by bacteria, and these communities were 451 probably from the rhizosphere soil at the early stage of truffle formation (Antony-Babu et al., 452 2013). Although the microbial diversity decreased, there were also some communities that 453 showed a higher abundance in the ectomycorrhizae and ectomycorrhizosphere. These 454 communities were thus closely related to the fomation of truffle mycorrhizae, possibly playing a 
455

456

457

458

459

460

461

462

463

464

465

466

467

468

469

470

471

472

473

474

475

476

477

478

479

480

role in ectomycorrhizal synthesis. However, the specific interactions between these microbial communities, ectomycorrhizosphere soil properties and truffles require further exploration.

\section{Conclusions}

This study revealed a significant effect of $T$. indicum inoculation on the $Q$. acutissima seedlings, the rhizosphere soil properties, and the microbial communities (bacteria and fungus) in root endosphere and rhizospher soil, which gave more details to the symbiosis of $Q$. acutissima with $T$. indicum. During the early symbiotic stage, changes in SOD activity, root activity and some rhizosphere soil properties (e.g., organic matter, total nitrogen, and available nitrogen) due to the $T$. indicum colonization may be the important factor that drove the changes in microbial communities. It was clear that the $T$. indicum inoculation did alter the diversity and structure of the microorganisms in root endosphere and rhizosphere soil, and certain bacteria and fungi were greatly different. Their specific roles playing in the truffle growth remained to be disclosed.

\section{Acknowledgements}

We would like to thank LetPub (www.letpub.com) for providing linguistic assistance during the preparation of this manuscript.

\section{References}

Alonso PR, Ágreda T, Águeda B, Aldea J, Martínez-Peña F, Modrego MP. 2014. Soil physical properties influence "black truffle" fructification in plantations. Mycorrhiza 24 Suppl 1(1):S55-64 DOI: https://doi.org/10.1007/s00572-014-0558-7.

Andrés-Alpuente A, Sánchez S, Martín M, Aguirre AJ, Barriuso JJ. 2014. Comparative analysis of different methods for evaluating quality of Quercus ilex seedlings inoculated with Tuber melanosporum. Mycorrhiza 24 Suppl 1(1):29-37 DOI: https: //doi.or g/10.1 007/s00572 -014- 0563-x.

Antony-Babu S, Deveau A, Van Nostrand JD, Zhou J, Le Tacon F, Robin C, Frey-Klett P, Uroz S. 2013. Black truffle-associated bacterial communities during the development and maturation of Tuber melanosporum ascocarps and putative functional roles. Environmental Microbiology 16(9): 2831-2847

Barbieri E, Guidi C, Bertaux J, Frey-Klett P, Garbaye J, Ceccaroli P, Saltarelli R, Zambonelli A, Stocchi 
481 V. 2007. Occurrence and diversity of bacterial communities in Tuber magnatum during truffle maturation. 482 Environmental Microbiology 9(9):2234-2246

483 Benucci GM and Bonito GM. 2016. The Truffle Microbiome: Species and Geography Effects on Bacteria 484 Associated with Fruiting Bodies of Hypogeous Pezizales. Microbial Ecology 72(1):4-8

485 Berendsen RL, Pieterse C.M.J, Bakker P.A.H.M. 2012. The rhizosphere microbiome and plant 486 health. Trends in Plant Science 17(8):478-486

487 Bonito G, Trappe JM, Donovan S, Vilgalysa R. 2011. The Asian black truffle Tuber indicum can form 488 ectomycorrhizas with North American host plants and complete its life cycle in non-native soils. Fungal 489 Ecology 4(1):83-93

490 Caporaso JG, Kuczynski J, Stombaugh J, Bittinger K, Bushman FD, Costello EK, Fierer N, Peña AG, 491 Goodrich JK, Gordon JI, Huttley GA, Kelley ST, Knights D, Koenig JE, Ley RE, Lozupone CA, 492 McDonald D, Muegge BD, Pirrung M, Reeder J, Sevinsky JR, Turnbaugh PJ, Walters WA, Widmann J, 493 Yatsunenko T, Zaneveld J, Knight R. 2010. QIIME allows analysis of high-throughput community 494 sequencing data. Nature Method 7(5): 335-336

495 Caporaso JG, Lauber CL, Walters WA, Berg-Lyons D, Huntley J, Fierer N, Owens SM, Betley J, Fraser L, 496 Bauer M, Gormley N, Gilbert JA, Smith G, Knight R. 2012. Ultra-high-throughput microbial community 497 analysis on the Illumina HiSeq and MiSeq platforms. The ISME Journal 6(8):1621-1624.

498 Chalot M and Brun A. 1998. Physiology of organic nitrogen acquisition by ectomycorrhizal fungi and 499 ectomycorrhizas. FEMS Microbiology Reviews 22(1):21-44

500 Che M, Wang R, Li X, Wang HY, Zheng XFS. 2016. Expanding roles of superoxide dismutases in cell 501 regulation and cancer. Drug Discovery Today 21(1):143-149

502 Dearnaley JD and Cameron DD. 2017. Nitrogen transport in the orchid mycorrhizal symbiosis- further 503 evidence for a mutualistic association. New Phytologist 213(1):10-12

504 Deng XJ, Yu FQ and Liu PG. 2014. Contribution to Confirmed \& Synthesized on Mycorrhizae of Tuber 505 indicum s.l. with Two Dominated \& Subalpine Broadleaf Trees in Southwestern China. American Journal 506 of Plant Sciences 5:3269-3279

507 Deveau A, Antony-Babu S, Le Tacon F, Robin C, Frey-Klett P, Uroz S. 2016. Temporal changes of 
508 bacterial communities in the Tuber melanosporum ectomycorrhizosphere during ascocarp development. 509 Mycorrhiza 26(5):389-399

510 Ding L, Zhao HM, Zheng WJ, Li Q, Wang Y, Wang SQ. 2017. Physiological responses of five plants in 511 northwest China arid area under drought stress. Chinese Journal of Applied Ecology 28 (5):1455-1463 [In 512 Chinese]

513 Dominguez JA, Martin A, Anriquez A, Albanesi A. 2012. The combined effects of Pseudomonas 514 fluorescens and Tuber melanosporum on the quality of Pinus halepensis seedlings. Mycorrhiza $51522(6): 429-436$

516 Domínguez Núñez JA, Planelles González R, Rodríguez Barreal JA, Saiz de Omeñaca González JA. 2008. 517 The effect of Tuber melanosporum Vitt. mycorrhization on growth, nutrition, and water relations of 518 Quercus petraea Liebl., Quercus faginea Lamk., and Pinus halepensis Mill. seedlings. New Forests $519 \quad 35(2): 159-171$

520 Doornbos RF, van Loon RC, Bakker P.A.H.M. 2012. Impact of root exudates and plant defense signaling 521 on bacterial communities in the rhizosphere. A review. Agronomy for Sustainable Development 32:227$522 \quad 243$

523 Edgar RC. 2010. Search and clustering orders of magnitude faster than BLAST. Bioinformatics 524 26(19):2460-2461

525 Fridovich I. 2011. Superoxide dismutases: anti- versus pro- oxidants? Anti-Cancer Agents in Medicinal 526 Chemistry (Formerly Current Medicinal Chemistry- Anti-Cancer Agents) 11(2):175-177

527 Fu Y, Li X, Li Q, Wu H, Xiong C, Geng Q, Sun H, Sun Q. 2016. Soil microbial communities of three 528 major Chinese truffles in southwest China. Canadian Journal of Microbiology 62(11): 1-10

529 Garcíamontero LG, Casermeiro MA, Hernando J, Hernando I. 2006. Soil factors that influence the 530 fruiting of Tuber melanosporum (black truffle). Australian Journal of Soil Research 44(8):731-738

531 Ge ZW, Timothy B, Gregory B, Matthew ES. 2017. Soil pH and mineral nutrients strongly influence 532 truffles and other ectomycorrhizal fungi associated with commercial pecans (Carya illinoinensis). Plant 533 Soil 418(1-2):493-505

534 Geng LY, Wang XH, Yu FQ, Deng XJ, Tian XF, Shi XF, Xie XD, Liu PG, Shen YY. 2009. Mycorrhizal 
535 synthesis of Tuber indicum with two indigenous hosts, Castanea mollissima and Pinus armandii. 536 Mycorrhiza 19(7):461-467.

537 Gerlach W and Nirenberg H, 1982. The genus Fusarium--a pictorial atlas. Mitteilungen aus der 538 Biologischen Bundesanstalt Fur Land- und Forstwirtschaft (Berlin-Dahlem) 209:1-405

539 Gryndler M and Hršelová H. 2012. Isolation of bacteria from ectomycorrhizae of Tuber aestivum Vittad. 540 Acta Mycologica 47(2):155-160

541 Gryndler M, Soukupová L, Hršelová H, Gryndlerová H, Borovička J, Streiblová E, Jansa J. 2013. A quest 542 for indigenous truffle helper prokaryotes. Environmental Microbiology Reports 5(3):346-352

543 Hardoim PR, Van Overbeek LS, Berg G, Pirttilä AM, Compant S, Campisano A, Döring M, Sessitsch A. 544 2015. The Hidden World within Plants: Ecological and Evolutionary Considerations for Defining 545 Functioning of Microbial Endophytes. Microbiology and Molecular Biology Reviews 79(3):293-320

546 Harley JL and Smith SE, 2008. Mycorrhizal symbiosis. Quarterly Review of Biology 3(3):273-281

547 Healy RA, Zurier H, Bonito G, Smith ME, Pfister DH. 2016. Mycorrhizal detection of native and non548 native truffles in a historic arboretum and the discovery of a new North American species, Tuber 549 arnoldianum sp. nov. Mycorrhiza 26(7): 781-792

$550 \mathrm{Hu}$ BF. 2004. The mycorrhizal Synthesis of Tuber indicum and Its Affect for Growth and against Disease 551 on the Seedlings. Guizhou Forestry Science and Technology 32(2): 19-24 [In Chinese]

552 Huang X, Liu L, Wen T, Zhu R, Zhang J, Cai Z, 2015. Illumina MiSeq investigations on the changes of 553 microbial community in the Fusarium oxysporum f.sp. cubense infected soil during and after reductive 554 soil disinfestation. Microbiological Research 181:33-42.

555 Kennedy P. 2010. Ectomycorrhizal fungi and interspecific competition: species interactions, community 556 structure, coexistence mechanisms, and future research directions. New Phytologist 187(4):895-910

557 Kües U and Martin F. 2011. On the road to understanding truffles in the underground. Fungal Genetics 558 and Biology 48(6):555-560

559 Li Q, Zhao J, Xiong C, Li X, Chen Z, Li P, Huang W. 2017. Tuber indicum shapes the microbial 560 communities of ectomycorhizosphere soil and ectomycorrhizae of an indigenous tree (Pinus armandii). 561 Plos One 12(4): e0175720 DOI 10.1371/journal.pone.0175720. 
562 Li Q, Li X, Chen C, Li S, Huang W, Xiong C, Jin X, Zheng L. 2016. Analysis of Bacterial Diversity and 563 Communities Associated with Tricholoma matsutake Fruiting Bodies by Barcoded Pyrosequencing in 564 Sichuan Province, Southwest China. Journal of Microbiology and Biotechnology 26(1):89-98

565 Lilleskova EA, Hobbieb EA, Horton TR. 2011. Conservation of ectomycorrhizal fungi: exploring the 566 linkages between functional and taxonomic responses to anthropogenic N deposition. Fungal Ecology 567 4(2):174-183

568 Liu PG, Wang Y, Wang XH, Chen J, Zheng HD, Deng XJ, Qiao P, Jang H, Tian XF, Zhang JP, Wan SP, 569 Wang R. 2011. Outline of Chinese Truffles and Their Conservational Strategies. Journal of Fungal 570 Research 9(4): 232-243.

571 Ludwig-Müller J. 2015. Plants and endophytes: equal partners in secondary metabolite production?

572 Biotechnology Letters 37(7):1325-1334

573 Magoč T and Salzberg SL. 2011. FLASH: fast length adjustment of short reads to improve genome 574 assemblies. Bioinformatics 27(21):2957-2963

575 Marjanović Ž, Glišić A, Mutavdžić D, Saljnikov E, Bragato G. 2015. Ecosystems supporting Tuber 576 magnatum Pico production in Serbia experience specific soil environment seasonality that may facilitate 577 truffle lifecycle completion. Applied Soil Ecology 95(9):179-190

578 Mello A, Ding GC, Piceno YM, Napoli C, Tom LM, DeSantis TZ, Andersen GL, Smalla K, Bonfante P. 579 2013. Truffle brûlés have an impact on the diversity of soil bacterial communities. Plos One 8(4): e61945 580 DOI: 10.1371/journal.pone.0061945.

581 Meloni DA, Oliva MA, Martinez CA, Cambraia J. 2003. Photosynthesis and activity of superoxide 582 dismutase, peroxidase and glutathione reductase in cotton under salt stress. Environmental and 583 Experimental Botany 49(1):69-76

584 Moore TR, Bubier JL, Frolking SE, Lafleur PM, Roulet NT. 2002. Plant biomass and production and $\mathrm{CO}_{2}$ 585 exchange in an ombrotrophic bog. Journal of Ecology 90(1):25-36.

586 R Core Team. 2014. R: A language and environment for statistical computing. Vienna, Austria. 587 https://doi.org/10.1016/B978-0-12-411511-8.09998-9

588 Río LAD, Corpas FJ, López-Huertas E, Palma JM. 2018. Plant Superoxide Dismutases: Function Under 
589 Abiotic Stress Conditions. In Antioxidants and Antioxidant Enzymes in Higher Plants (pp. 1-26). 590 Springer, Cham. DOI: 10.1007/978-3-319-75088-0_1

591 Shabala S, Pang J, Zhou M, Shabala L, Cuin TA, Nick P, Wegner LH. 2009. Electrical signalling and 592 cytokinins mediate effects of light and root cutting on ion uptake in intact plants. Plant Cell and 593 Environment 32(2):194-207

594 Slankis V. 1974. Soil Factors Influencing Formation of Mycorrhizae. Annual Review of Phytopathology 595 12(1):437-457

596 Song R, Deng X, Song XS. 2016. Progress of Researches on Interaction Mechanism between 597 Ectomycorrhizal Fungi and Mycorrhizal Helper Bacteria. Journal of Jilin Agricultural University 598 38(4):379-384 [In Chinese]

599 Splivallo R, Deveau A, Valdez N, Kirchhoff N, Frey-Klett P, Karlovsky P. 2015. Bacteria associated with 600 truffle - fruiting bodies contribute to truffle aroma. Environmental Microbiology 17(8):2647-2660

601 Splivallo R, Novero M, Bertea CM, Bossi S, Bonfante P. 2007. Truffle Volatiles Inhibit Growth and 602 Induce an Oxidative Burst in Arabidopsis thaliana. New Phytologist 175(3): 417-424

603 Streiblová E, Gryndlerová H, Gryndler M. 2012. Truffle brûlé: An efficient fungal life strategy. FEMS 604 Microbiology Ecology 80(1):1-8

605 Taïbi K, Taïbi F, Abderrahim LA, Ennajah A, Belkhodja M, Mulet JM. 2016. Effect of salt stress on 606 growth, chlorophyll content, lipid peroxidation and antioxidant defence systems in Phaseolus vulgaris L.. 607 South African Journal of Botany 105:306-312.

608 Valverde-Asenjo I, García-Montero LG, Quintana A, Velázquez J. 2009. Calcareous amendments to soils 609 to eradicate Tuber brumale from T. melanosporum cultivations: a multivariate statistical approach. 610 Mycorrhiza 19(3):159-165

611 Wan SP, Yu FQ, Tang L, Wang R, Wang Y, Liu PG, Wang XH, Zheng Y. 2015. Ectomycorrhizae of 612 Tuber huidongense and T. liyuanum with Castanea mollissima and Pinus armandii. Mycorrhiza 26(3):1-8 613 Wang R, Liu PG, Wan SP, Yu FQ. 2015. Study on mycorrhization helper bacteria (MHB) of Tuber 614 indicum. Microbiology China 42(12):2366-2376 [In Chinese]

615 Ye L, Li Q, Fu Y, Sourzat P, Tan H, Zou J, Zhang B, Li XL. 2018. Host species effects on bacterial 
616 communities associated with the fruiting bodies of Tuber species from the Sichuan Province in Southwest 617 China. Mycological Progress 17(7):830-840

618 Yin X and Zhu Z. 2008. Study on Physiology of Water Stress and Characteristics of Drought Tolerance in 619 Mycorrhizal Fungi Seedlings of Pinus massoniana. Forest Resources Management 6(3) 63-67 [In 620 Chinese]

621 Zampieri E, Chiapello M, Daghino S, Bonfante P, Mello A. 2016. Soil metaproteomics reveals an inter622 kingdom stress response to the presence of black truffles. Scientific Report 10 (6):25773 DOI: $62310.1038 /$ srep25773.

624 Zhang CX, He MX, Gao F, Liu J, Cao Y, X XJ, Wang WB, Wang Y. 2015. Study on Mycorrhizal 625 Synthesis of Tuber indicum with Pinus kesiya var. langbianensis. Southwest China Journal of 626 Agricultural Sciences 28(1):329-332 [In Chinese]

627 Zhang X, Huang G, Bian X, Zhao Q. 2013. Effects of root interaction and nitrogen fertilization on the 628 chlorophyll content, root activity, photosynthetic characteristics of intercropped soybean and microbial 629 quantity in the rhizosphere. Plant Soil and Environment 59(2):80-88

630 Zhou J and Wei H. 2013. rDNA-ITS Sequence Analysis Identify Truffle-associated Fungi. Journal of 631 Xinyang Normal University 3(3):379-381 [In Chinese] 


\section{Table $\mathbf{1}$ (on next page)}

The root activity, biomass, leaf chlorophyll content, root superoxide dismutases (SOD) activity and root peroxidase (POD) activity of $Q$. acutissima with $T$. indicum mycorrhization or not.

Ectomycorrhizae, ectomycorrhizae from $Q$. acutissima mycorrhized with $T$. indicum. Control roots, roots from cultivated $Q$. acutissima without $T$. indicum colonization. "FW" means fresh weight of the root. Value followed "*" symbol indicates a significant difference between samples $(P<0.05)$. Each value is the mean of 3 replicates $( \pm S D)$. 
1

\begin{tabular}{lccccc}
\hline Samples & POD activity & SOD activity & Root activity & Biomass & Chlorophyll \\
& $\mathrm{U} /(\mathrm{g} \cdot \mathrm{min}) \mathrm{FW}$ & $\mathrm{U} /(\mathrm{g} \cdot \mathrm{h}) \mathrm{FW}$ & $\mathrm{ug} /(\mathrm{g} * \mathrm{~min}) \mathrm{FW}$ & $(\mathrm{g})$ & $\mathrm{mg} / \mathrm{g} \mathrm{FW}$ \\
\hline Ectomycorrhizae & $14.93 \pm 6.99$ & $102.47 \pm 2.58$ & $26.25 \pm 5.16$ & $3.02 \pm 0.81$ & $28.62 \pm 5.43$ \\
\hline Control roots & $17.20 \pm 6.15$ & $68.25 \pm 1.77^{*}$ & $40.95 \pm 4.27^{*}$ & $2.92 \pm 0.32$ & $32.48 \pm 3.68$ \\
\hline
\end{tabular}




\section{Table 2 (on next page)}

Physical and chemical properties of $Q$. acutissima rhizosphere soil and ectomycorrhizosphere soil.

OM, organic matter; TN, total nitrogen; TP, total phosphorus; TK, total potassium; AN, available nitrogen; AP, available phosphorus; AK, available potassium; ACa, available calcium; AMg, available magnesium. Value followed "*" symbol indicates a significant difference between samples $(P<0.05)$. Each value is the mean of 3 replicates $( \pm S D)$. 


\begin{tabular}{|c|c|c|c|c|c|c|c|c|c|c|}
\hline Samples & pH & OM g/kg & TN g/kg & TP g/kg & TK g/kg & AN mg/kg & AP mg/kg & $\begin{array}{c}\mathrm{AK} \\
\mathrm{mg} / \mathrm{kg}\end{array}$ & $\begin{array}{c}\text { ACa cmol } \\
\left(1 / 2 \mathrm{Ca}^{2+}\right) \\
\quad / \mathbf{k g}\end{array}$ & $\begin{array}{l}\text { AMg cmol } \\
\left(1 / 2 \mathrm{Mg}^{2+}\right) \\
\quad / \mathbf{k g}\end{array}$ \\
\hline $\begin{array}{l}\text { Ectomycorrhizosphere } \\
\text { soil }\end{array}$ & $8.27 \pm 0.01$ & $\begin{array}{l}23.27 \pm \\
0.21\end{array}$ & $0.610 \pm 0.00$ & $1.27 \pm 0.05$ & $22.21 \pm 0.42$ & $388.00 \pm 1.73$ & $72.23 \pm 1.29$ & $\begin{array}{c}652.67 \pm \\
4.72\end{array}$ & $39.37 \pm 0.93$ & $7.77 \pm 0.29$ \\
\hline $\begin{array}{c}\text { Control soil (rhizosphere } \\
\text { soil without } T \text {. indicum } \\
\text { associations ) }\end{array}$ & $8.54 \pm 0.04 *$ & $\begin{array}{l}22.53 \pm \\
0.12^{*}\end{array}$ & $0.602 \pm 0.00^{*}$ & $1.16 \pm 0.02 *$ & $22.17 \pm 0.55$ & $364.33 \pm 2.52^{*}$ & $80.50 \pm 1.73 *$ & $\begin{array}{c}676.33 \pm \\
3.21^{*}\end{array}$ & $59.27 \pm 0.65^{*}$ & $7.77 \pm 0.21$ \\
\hline
\end{tabular}




\section{Table 3 (on next page)}

Community richness and diversity indices of bacteria (a) and fungus (b) associated with $Q$. acutissima roots and rhizosphere soils with or without $T$. indicum mycorrhization.

A, ectomycorrhizae from $Q$. acutissima mycorrhized with $T$. indicum. B, the ectomycorrhizosphere soil of $Q$. acutissima. C, the rhizosphere soil without $T$. indicum associations (control soil). D, roots from cultivated $Q$. acutissima without $T$. indicum colonization (control roots). Each value is the mean of 3 replicates $( \pm S D)$. Values followed by different lowercase letters indicate significant differences $(P<0.05)$ between samples in a line. 
1

2

a

\begin{tabular}{cccccc}
\hline Samples & OUT & Chao1 & Shannon & Simpson & Coverage \\
\hline A & $759.33 \pm 94.48 \mathrm{a}$ & $938 \pm 122.44 \mathrm{a}$ & $3.06 \pm 0.43 \mathrm{a}$ & $0.20 \pm 0.07 \mathrm{a}$ & $0.9923 \pm 0.0011 \mathrm{a}$ \\
B & $908.67 \pm 26.39 \mathrm{a}$ & $1101 \pm 47.84 \mathrm{a}$ & $5.21 \pm 0.07 \mathrm{~b}$ & $0.02 \pm 0.00 \mathrm{~b}$ & $0.9895 \pm 0.0004 \mathrm{~b}$ \\
C & $1333.67 \pm 11.06 \mathrm{~b}$ & $1464.33 \pm 10.97 \mathrm{~b}$ & $5.81 \pm 0.08 \mathrm{c}$ & $0.01 \pm 0.00 \mathrm{~b}$ & $0.9923 \pm 0.0005 \mathrm{a}$ \\
D & $767.33 \pm 169.51 \mathrm{a}$ & $997 \pm 228.68 \mathrm{a}$ & $2.32 \pm 0.20 \mathrm{~d}$ & $0.36 \pm 0.03 \mathrm{c}$ & $0.9923 \pm 0.0022 \mathrm{a}$ \\
\hline
\end{tabular}

3

4

b

\begin{tabular}{llllll}
\hline Samples & OUT & Chao & Shannon & Simpson & Coverage \\
\hline A & $38.33 \pm 2.31 \mathrm{a}$ & $58.33 \pm 24.91 \mathrm{a}$ & $0.42 \pm 0.08 \mathrm{a}$ & $0.84 \pm 0.03 \mathrm{a}$ & $0.9997 \pm 0.0006 \mathrm{a}$ \\
B & $118.33 \pm 6.66 \mathrm{~b}$ & $140.33 \pm 5.13 \mathrm{~b}$ & $0.91 \pm 0.47 \mathrm{a}$ & $0.74 \pm 0.16 \mathrm{a}$ & $0.9995 \pm 0.0035 \mathrm{ab}$ \\
$\mathrm{C}$ & $176 \pm 5 \mathrm{c}$ & $192.67 \pm 5.86 \mathrm{c}$ & $2.89 \pm 0.42 \mathrm{~b}$ & $0.14 \pm 0.07 \mathrm{~b}$ & $0.9993 \pm 0.0006 \mathrm{bc}$ \\
\hline D & $143.33 \pm 7.23 \mathrm{~d}$ & $175 \pm 20.81 \mathrm{c}$ & $2.02 \pm 0.19 \mathrm{c}$ & $0.27 \pm 0.08 \mathrm{~b}$ & $0.9991 \pm 0.0020 \mathrm{c}$ \\
\hline
\end{tabular}

5 


\section{Figure 1}

The ectomycorrhizae of $Q$. acutissima with $T$. indicum $(a, b, c)$ and the root tips of $Q$. acutissima that were not colonized by $T$. indicum (d).

Photo credit: Lei Ye.

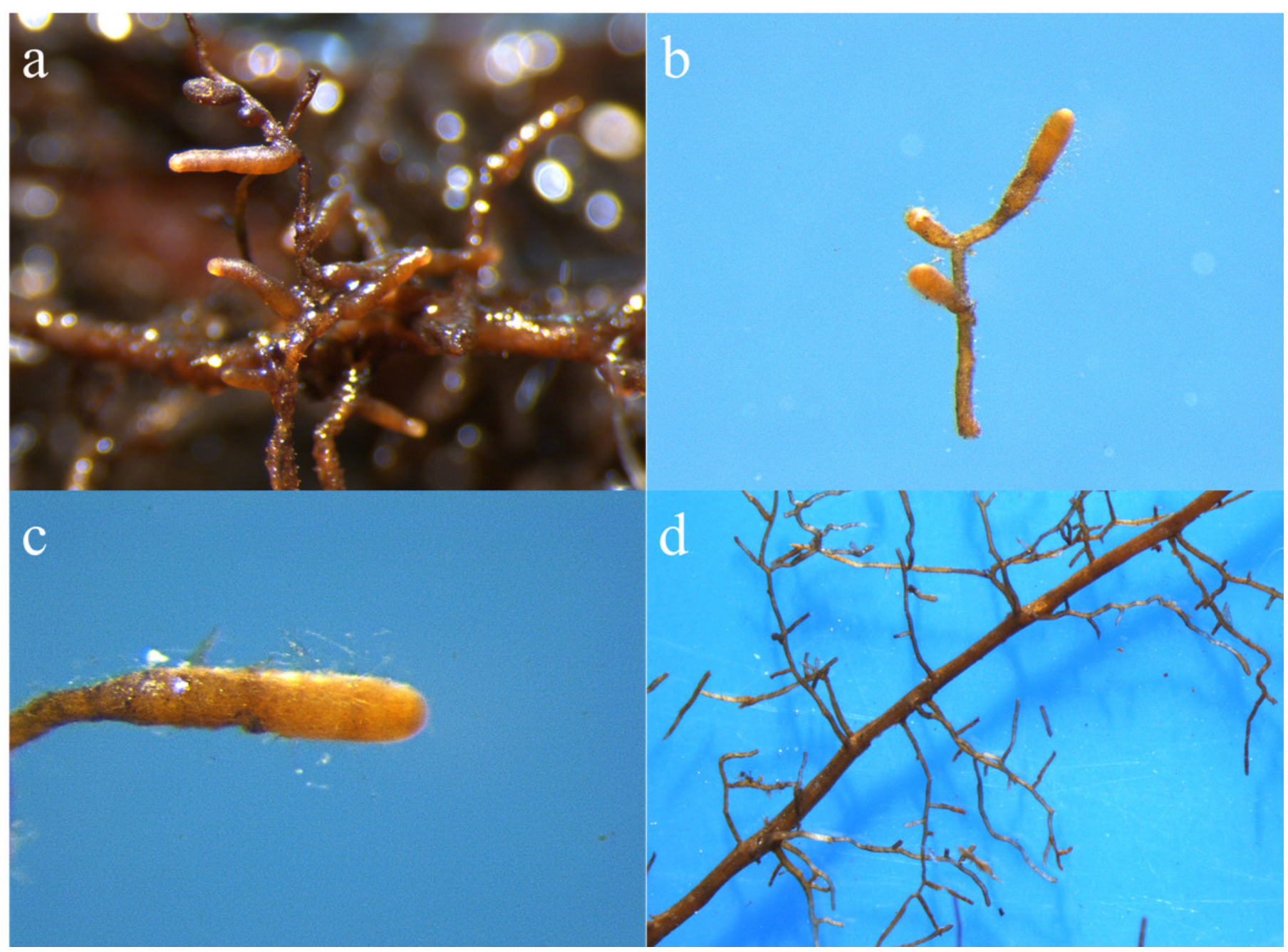


Figure 2

The morphological characteristics of $T$. indicum ectomycorrhizae $(a, b)$ and control roots tips that were not colonized by $T$. indicum $(c, d)$.

$a$ and $c$, transversal sections; $b$ and $d$, longitudinal sections.

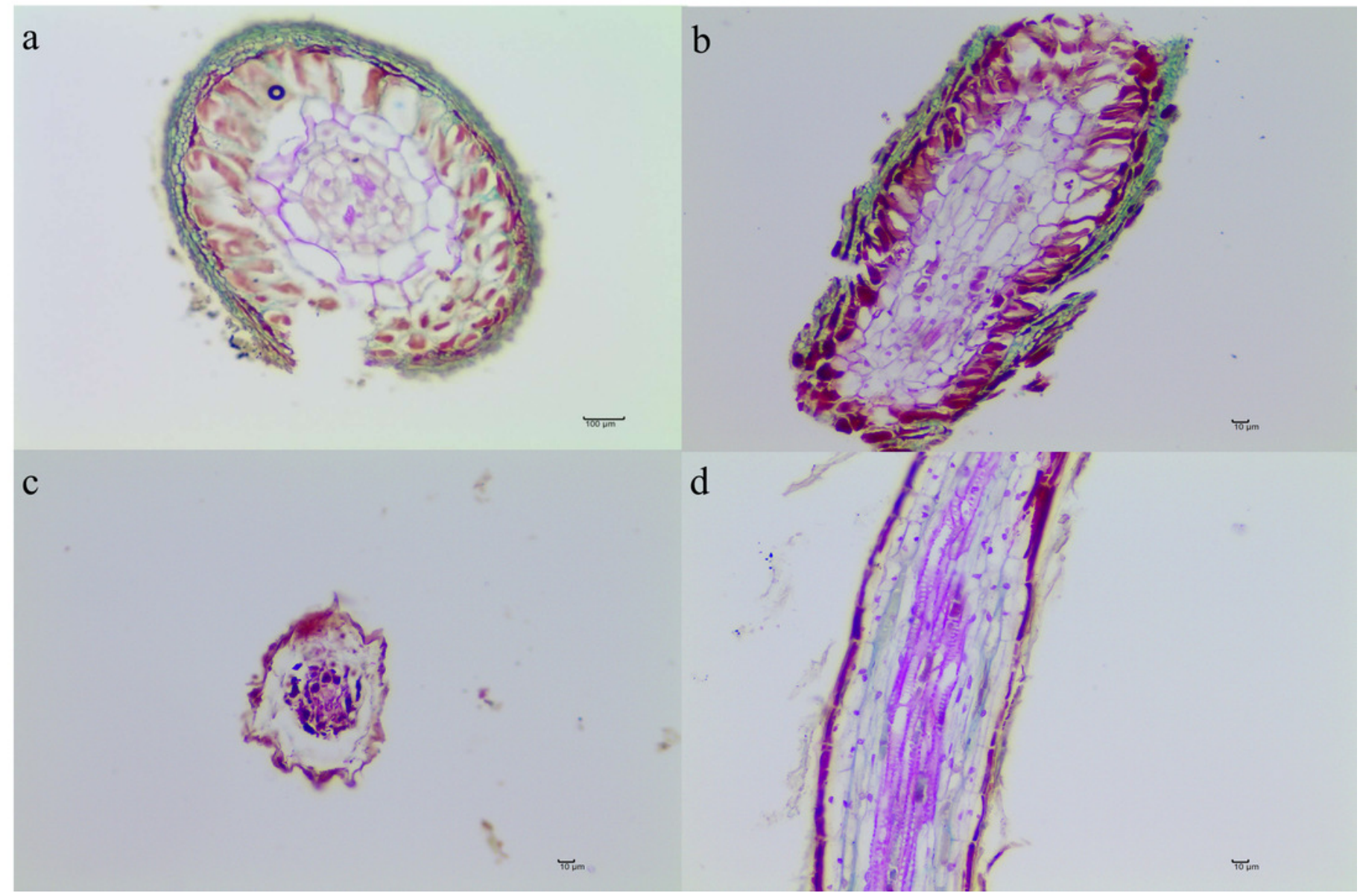


Figure 3

Shared and unique bacterial (a) and fungal (b) OTUs among samples in different treatments.

A, ectomycorrhizae from $Q$. acutissima mycorrhized with $T$. indicum. B, the ectomycorrhizosphere soil of $Q$. acutissima. C, the rhizosphere soil without $T$. indicum associations (control soil). D, roots from cultivated $Q$. acutissima without $T$. indicum colonization (control roots).
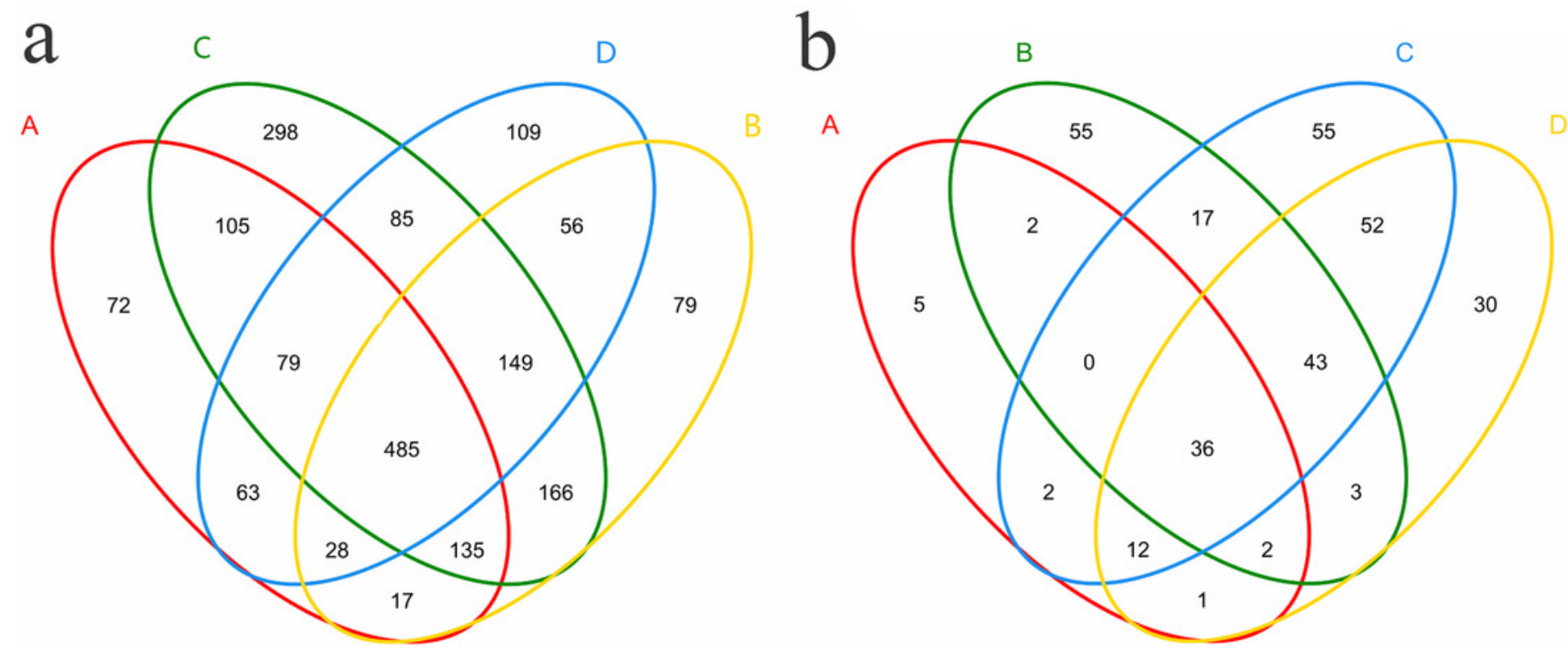


\section{Figure 4}

Nonmetric Multidimensional Scaling ordination showing the weighted UniFrac dissimilarities of bacterial (a) and fungal (b) communities in the roots and soil with $T$. indicum associations or not.

A, ectomycorrhizae from $Q$. acutissima mycorrhized with $T$. indicum. B, the ectomycorrhizosphere soil of $Q$. acutissima. C, the rhizosphere soil without $T$. indicum associations (control soil). D, roots from cultivated $Q$. acutissima without $T$. indicum colonization (control roots).
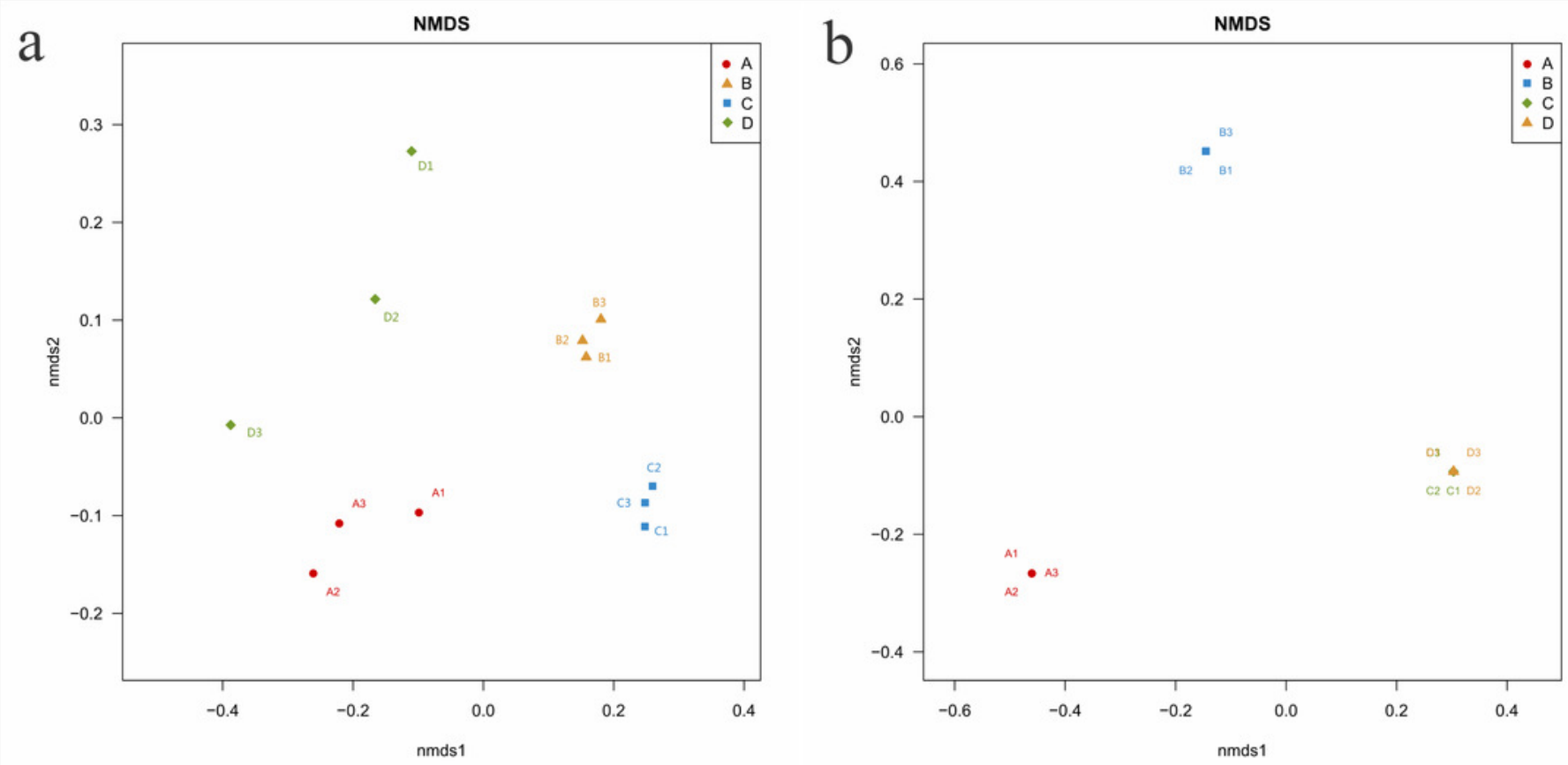


\section{Figure 5}

Taxonomic composition of bacterial and fungal communities associated with $Q$. acutissima root tips and rhizosphere soils at the phylum levels.

(a) bacterial phyla; (b) fungal phyla. A, ectomycorrhizae from Q. acutissima mycorrhized with T. indicum. B, the ectomycorrhizosphere soil of $Q$. acutissima. C, the rhizosphere soil without T. indicum associations (control soil). D, roots from cultivated Q. acutissima without $T$. indicum colonization (control roots). "norank" means there is no scientific name for this hierarchy in the taxonomic family tree. "Unclassified" means under the confidence threshold, it cannot be compared with the database. All experiments were conducted with three replicates.
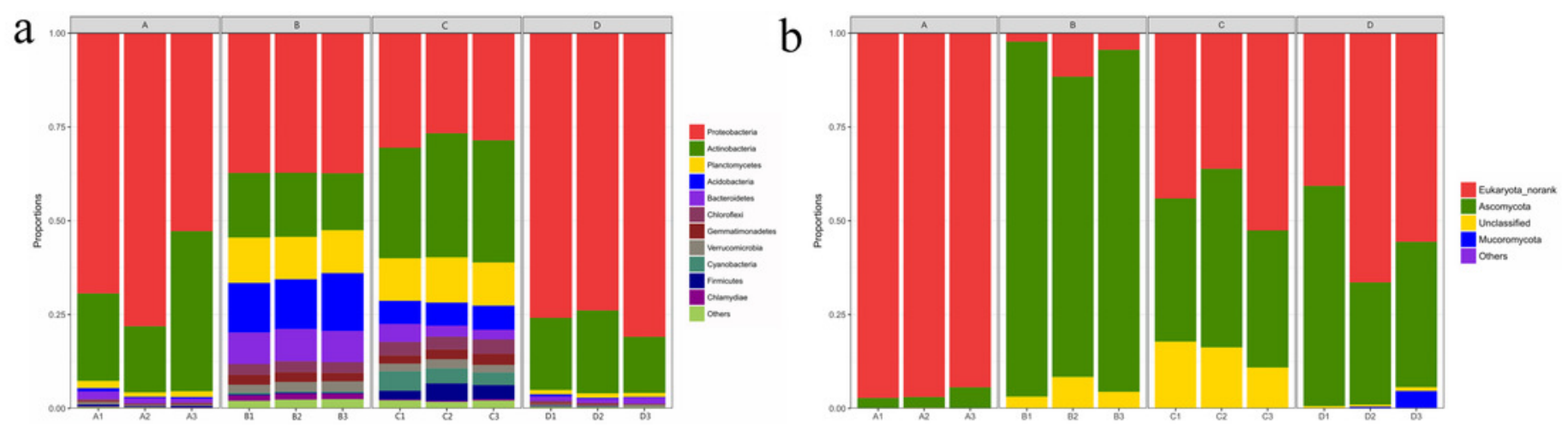


\section{Figure 6}

The Cladogram based on LEfSe analysis ( $P<0.05$, LDA score $>2$ ) showing the significantly differentially abundant bacterial (a) and fungal (b) taxa in the roots and soil with $T$. indicum inoculation treatments or not.

A, ectomycorrhizae from $Q$. acutissima mycorrhized with $T$. indicum. B, the ectomycorrhizosphere soil of $Q$. acutissima. C, the rhizosphere soil without $T$. indicum associations (control soil). D, roots from cultivated $Q$. acutissima without $T$. indicum colonization (control roots). 


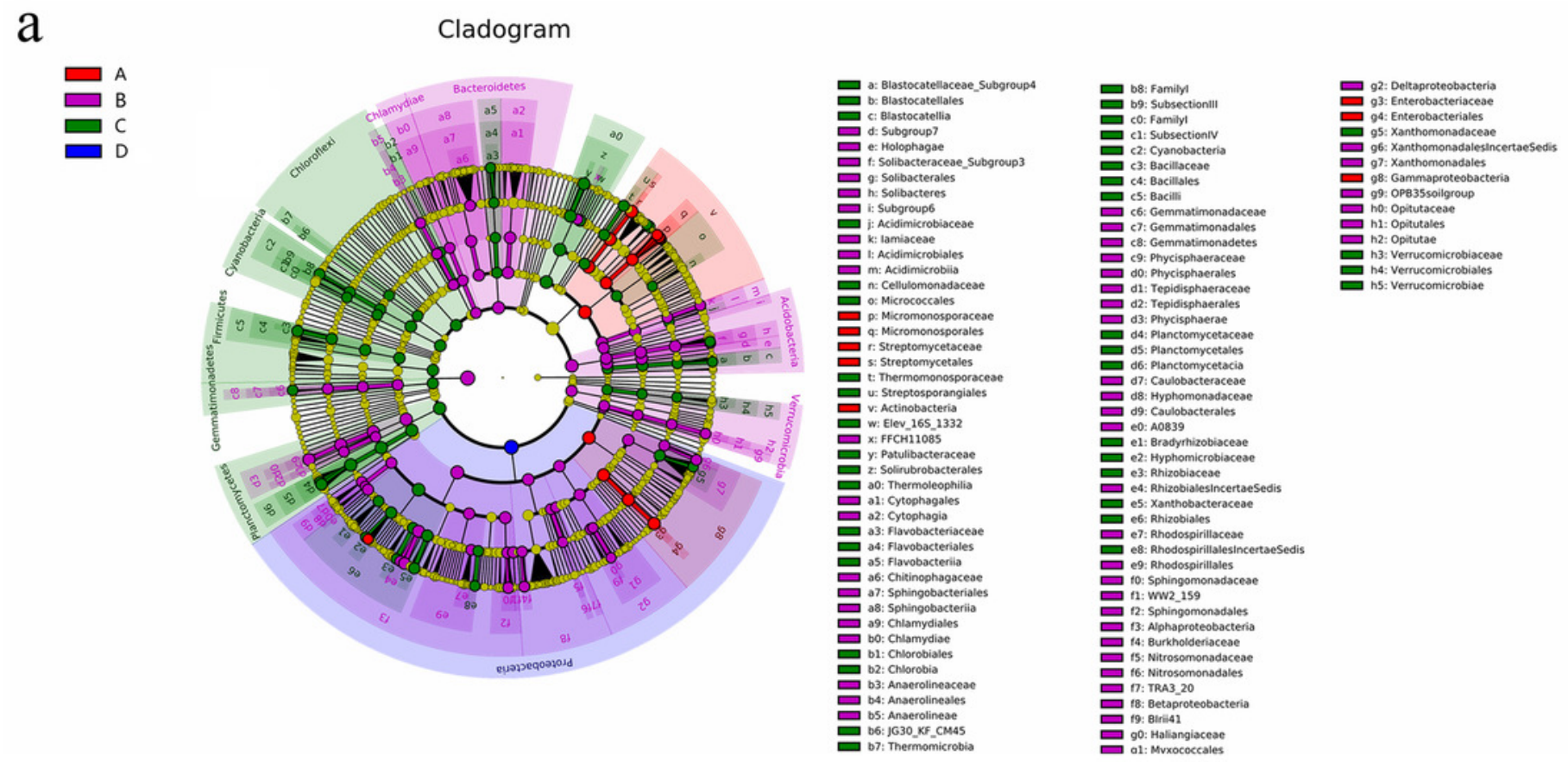

b

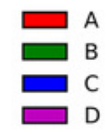

Cladogram
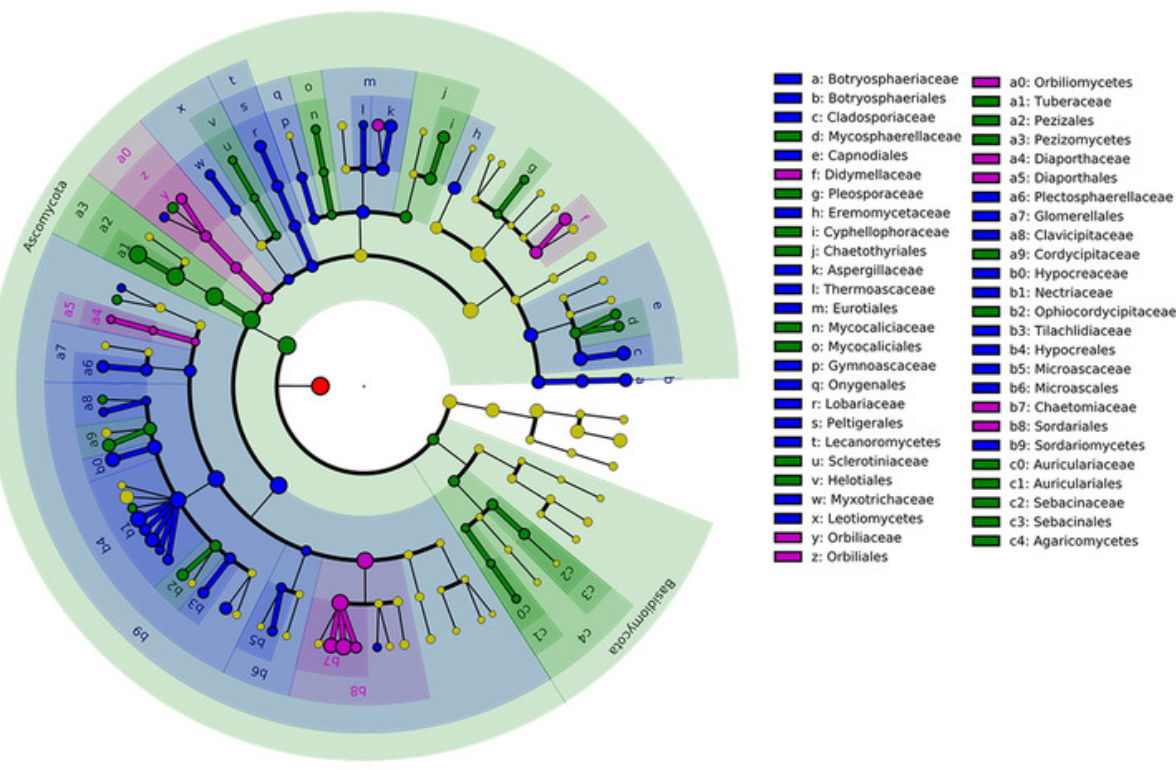


\section{Figure 7}

Heat-map analysis of the 50 most abundant bacterial and fungal genera in roots and soil communities of $Q$. acutissima.

(a) bacterial genera; (b) fungal genera. A, ectomycorrhizae from Q. acutissima mycorrhized with $T$. indicum. B, the ectomycorrhizosphere soil of $Q$. acutissima. C, the rhizosphere soil without $T$. indicum associations (control soil). D, roots from cultivated $Q$. acutissima without $T$. indicum colonization (control roots). The relative abundances of OTUs at the genus level are colored according to the color scales at the bottom of each heatmap. 
a
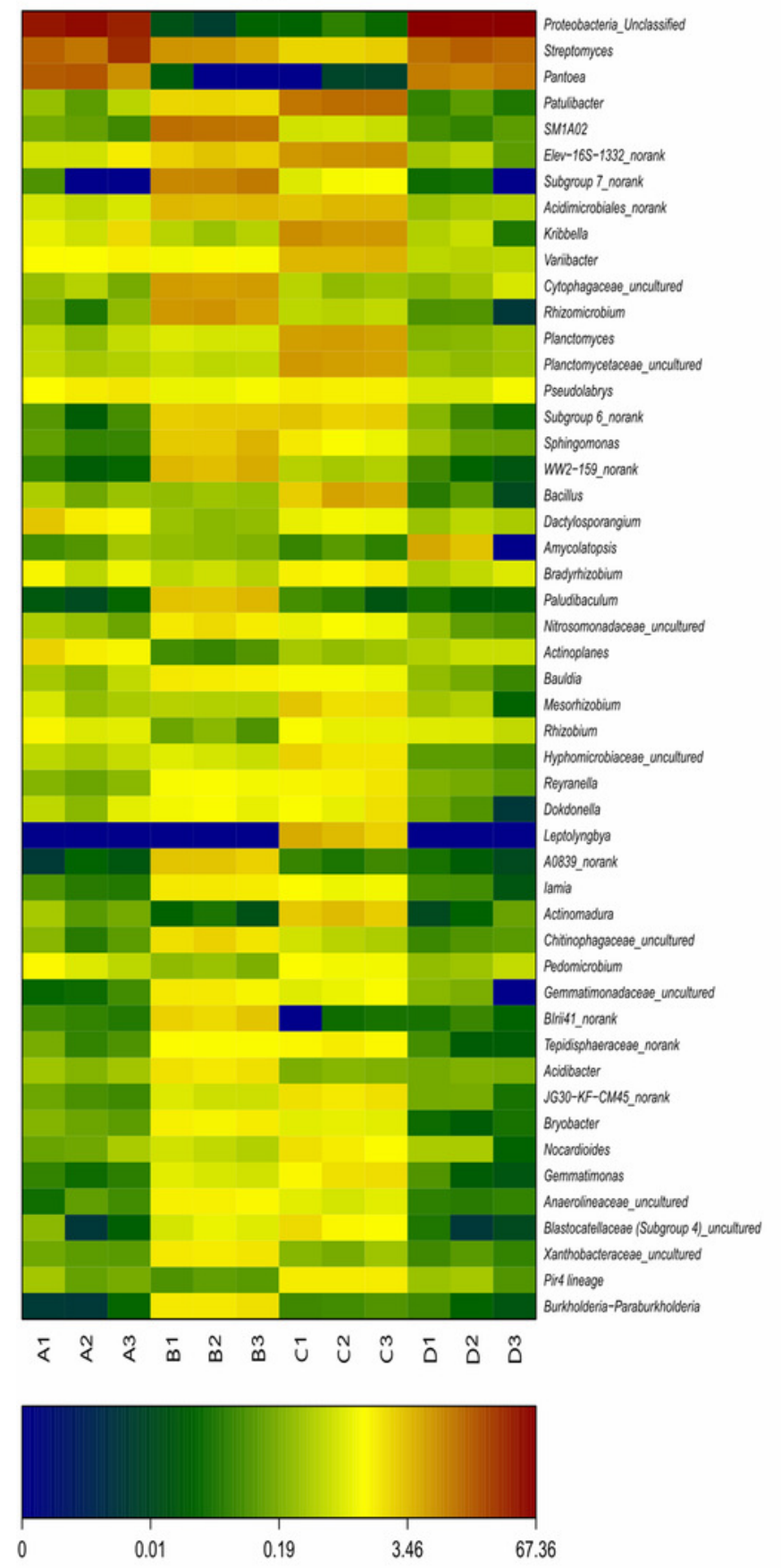

Relative abundance of community $(\%)$ b
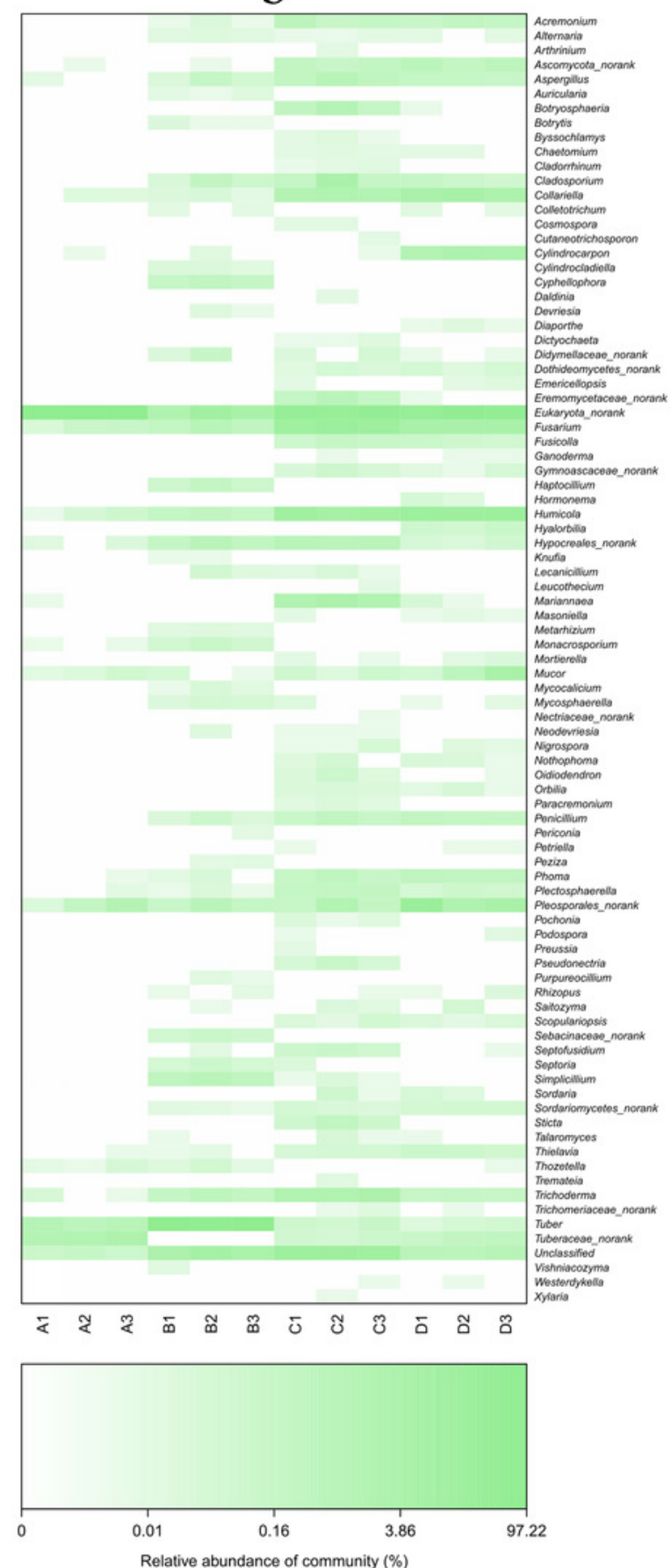